\title{
Carvacrol suppresses proliferation and invasion in human oral squamous cell carcinoma
}

\author{
This article was published in the following Dove Press journal: \\ OncoTargets and Therapy \\ 18 April 2016 \\ Number of times this article has been viewed
}

\author{
Wei Dai ${ }^{1,2}$ \\ Changfu Sun ${ }^{1,2}$ \\ Shaohui Huang ${ }^{1,2}$ \\ Qing Zhou ${ }^{1,2}$ \\ 'Department of Oromaxillofacial- \\ Head and Neck Surgery, ${ }^{2}$ Department \\ of Oral and Maxillofacial Surgery, \\ School of Stomatology, China Medical \\ University, Shenyang, Liaoning, \\ People's Republic of China
}

\begin{abstract}
Carvacrol, a component of thyme oil, as a novel antitumor agent, has been implicated in several types of cancer cells. However, the mechanisms underlying the effect of carvacrol in human oral squamous cell carcinoma (OSCC) remain unclear. Here, we report that carvacrol significantly inhibits tumor cell proliferation, metastasis and invasion, and induces apoptosis in OSCC. Our results demonstrated that the molecular mechanisms of the effect of carvacrol in Tca-8113 induces G1/S cell cycle arrest through downregulation of CDK regulator CCND1 and CDK4, and upregulation of CDK inhibitor P21. Further analysis demonstrated that carvacrol also inhibited Tca-8113 cells' clone formation in clonogenic cell survival assay. Student's $t$-test (two-tailed) was used to compare differences between groups, and the significance level was $P<0.01$. Then, treatment of Tca- 8113 cells with carvacrol resulted in downregulation of Bcl-2, Cox2, and upregulation of Bax. Carvacrol significantly inhibited the migration and invasion of human OSCC cells by blocking the phosphorylation of FAK and MMP-9 and MMP-2, transcription factor ZEB1, and $\beta$-catenin proteins' expression. Taken together, these results provide novel insights into the mechanism of carvacrol and suggest potential therapeutic strategies for human OSCC.
\end{abstract}

Keywords: carvacrol, proliferation, metastasis and invasion, oral squamous cell carcinoma

\section{Introduction}

Tongue cancer, a common malignancy of oral squamous cell carcinoma (OSCC), is poorly responsive to traditional therapies such as radiation therapy and chemotherapy. ${ }^{1,2}$ Recently, researchers have focused on targeted molecular therapy, immunotherapy, and traditional Chinese medicine monomers. ${ }^{3-5}$ Our previous studies showed that monoclonal antibody cetuximab is a potential therapeutic strategy for OSCC. ${ }^{6}$

Carvacrol is a natural isopropyl cresol, which is found in essential oils of the family Lamiaceae, including the genera Origanum and Thymus. ${ }^{7,8}$ Previous studies have demonstrated that carvacrol has analgesic, antimicrobial, anti-inflammatory, antioxidant, and antiangiogenic properties. ${ }^{9-17}$ Furthermore, carvacrol was reported to have an anti-proliferative effect on lung, breast, and colon cancer cell lines, ${ }^{18-20}$ but the effect of carvacrol on OSCC proliferation, apoptosis, and metastasis remains to be determined.

The main purpose of our study was to investigate the feasibility of carvacrol as a noble and strategic treatment modality for OSCC. The main hypothesis is that carvacrol could significantly alter the expression levels of several proteins related to proliferation, apoptosis, and metastasis in OSCC in vitro. The enzyme Cox 2 is only produced during inflammation, cell proliferation, and differentiation. ${ }^{21}$ Studies demonstrated that the decreased expression of Cox 2 in cancer cell lines induced cancer cell
Department of Oromaxillofacial-Head and Neck Surgery, School of Stomatology, China Medical University, No II 7 Nanjing North Street, Heping District, Shenyang I I0002, Liaoning,

People's Republic of China

Email cmudaiwei@gmail.com (c) (i) (5) 2016 Dai et al. This work is published and licensed by Dove Medical Press Limited. The full terms of this license are available at https://www.dovepress.com/terms.php cc. ${ }_{\mathrm{BY}} \mathrm{NC}$ and incorporate the Creative Commons Attribution - Non Commercial (unported, v3.0) License (http://creativecommons.org/licenses/by-nd/3.0/). By accessing the work you hereby accept the Terms. Non-commercial uses of the work are permitted without any further permission from Dove Medical Press Limited, provided the work is properly attributed. For permission for commercial use of this work, please see paragraphs 4.2 and 5 of our Terms (https://www.dovepress.com/terms.php). 
apoptosis. The zinc finger transcriptional repressor, ZEB1, inhibits E-cadherin expression. Loss of E-cadherin is associated with tumor invasiveness, metastatic dissemination, and poor prognosis in several solid tumors. ${ }^{22} \mathrm{Bcl}-2$ is a member of anti-apoptotic proteins, which regulate mitochondrial dysfunction. The increased cell apoptosis was accompanied by a decrease in anti-apoptotic Bcl-2 expression and an increase in pro-apoptotic Bax expression.

Here, our data show that carvacrol significantly reduced the proliferation and induced apoptosis by regulating the cell cycle-associated proteins (P21, CCND1 and CDK4) and apoptosis-associated proteins (Cox2, Bcl-2, and Bax). Furthermore, carvacrol suppressed the migration and invasion of Tca-8113 cell lines by inhibiting P-FAK, and reducing $\beta$-catenin, ZEB1, and MMP-2/9 expression. Based on obtained results, we conclude that carvacrol plays critical roles in cell cycle, cell invasion, and metastasis signaling pathways.

\section{Materials and methods}

\section{Reagents and antibodies}

Cell culture reagents were obtained from Gibco-Invitrogen (Thermo Fisher Scientific, Waltham, MA, USA). Carvacrol was purchased from Sigma-Aldrich Co. (St Louis, MO, USA). P21, CDK2, CDK4, CDK6, CCND1, Cox2, Bcl-2, Bax, FAK, p-FAK, ZEB1, and $\beta$-catenin were purchased from Cell Signaling Technology (Danvers, MA, USA). $\beta$-actin was purchased from Beijing Zhongshan Goldenbridge Biotechnology (Beijing, People's Republic of China) and GAPDH was purchased from ShangHai Kangchen (Shanghai, People's Republic of China). MMP-2 and MMP-9 were purchased from Santa Cruz Biotechnology Inc. (Dallas, TX, USA).

\section{Cell culture}

Human OSCC Tca-8113 and SCC-25 cell lines were obtained from GeneChem Co., Ltd (Shanghai, People's Republic of China). The cells were cultured in Dulbecco's Modified Eagle's Medium (DMEM) (Gibco) plus 10\% heat-inactivated fetal bovine serum (FBS), $100 \mathrm{IU} / \mathrm{mL}$ penicillin and $100 \mu \mathrm{g} / \mathrm{mL}$ streptomycin at $37^{\circ} \mathrm{C}$ in a $5 \% \mathrm{CO}_{2}$ incubator. The use of human OSCC cell lines was approved by the ethics committee of the China Medical University.

\section{Treatments}

Tca-8113 cells were plated in standard DMEM in 24-well or 6 -well dishes, respectively, 24 hours after plating and 8 hours prior to treatment with carvacrol, medium was exchanged with fresh DMEM (no FBS). Cells were treated with the indicated concentration of carvacrol and afterward lysed for Western blotting. Control cultures received the same volume of dimethyl sulfoxide (DMSO).

\section{MTT proliferation assay}

Tca-8113 and SCC-25 cells were digested and reseeded in 96-well plates $\left(5 \times 10^{3}\right)$ for cell viability assay. Cells were incubated with $10 \mu \mathrm{L}$ MTT $(10 \mathrm{mg} / \mathrm{mL})$ at $37^{\circ} \mathrm{C}$ for 4 hours, supernatants were discarded carefully, and $200 \mu \mathrm{L}$ DMSO was added to solubilize the formazan product for 20 minutes at room temperature. The spectrophotometric absorbance of each sample was measured at $490 \mathrm{~nm}$. All the experiments were repeated in triplicate.

\section{Western blotting analysis}

Tca-8113 whole cell extracts were collected in radioimmunoprecipitation assay lysis buffer $(50 \mathrm{mM}$ Tris/ $\mathrm{HCl} \mathrm{pH} 7.4$, $150 \mathrm{mM} \mathrm{NaCl}, 1 \%$ NP-40, 0.25\% Na-deoxycholate, $1 \mathrm{mM}$ ethylenediaminetetraacetic acid, and protease inhibitor cocktail). Next, $50 \mu \mathrm{g}$ of total protein was separated through sodium dodecyl sulfate polyacrylamide gel electrophoresis and transferred to PVDF membranes (GE Healthcare BioSciences Corp., Piscataway, NJ, USA). The membranes were blocked at room temperature for 1 hour in Tris-buffered saline and Tween-20 and 5\% fat-free powdered milk, and incubated overnight with specific antibodies at $4^{\circ} \mathrm{C}$. After incubation with the primary antibody, the membrane was then incubated with the secondary antibody for 2 hours, and washed in triplicate for 10 minutes in Tris-buffered saline and Tween-20 prior to chemiluminescence detection (GE Healthcare Bio-Sciences Corp.).

\section{Colony forming assay}

Tca- 8113 cells were cultured in a 6 -well tissue culture plate at $1 \times 10^{3}$ cells/well. Cells were grown for 15 days. Colonies were fixed by $4 \%$ paraformaldehyde and stained with crystal violet to enable enumeration of colonies.

\section{Cell adhesion assay}

Tca-8113 cells were suspended in $0.1 \%$ BSA/DMEM $\left(2 \times 10^{4}\right.$ cells $\left./ 500 \mu \mathrm{L}\right)$, and seeded onto a fibronectin-coated 24-well Primaria culture dish $(500 \mu \mathrm{L} /$ well $)$. After incubation in a $5 \% \mathrm{CO}_{2}$ incubator for 60 minutes or 100 minutes, nonadherent cells were removed by gently washing twice with $1 \mathrm{~mL}$ of phosphate-buffered saline (PBS). Then, following fixation with $500 \mu \mathrm{L}$ of $4 \%$ paraformaldehyde in PBS per well at $4^{\circ} \mathrm{C}$ for 5 minutes, the adhesive cells were stained with $0.4 \%$ Trypan Blue and counted under fluorescent microscopy.

\section{Apoptosis and cell cycle analysis}

For apoptosis, the annexin V-FITC apoptosis detection kits (BD Biosciences, San Jose, CA, USA) were used according to the manufacturer's instructions. Cells were harvested 
directly or 24 hours after carvacrol treatment and washed with ice-cold PBS, a FACScan instrument (BD, Franklin Lakes, NJ, USA) was used to detect apoptosis in cells. The experiment was repeated in triplicate. For cell cycle analysis, cells were trypsinized, washed with PBS, and fixed in 70\% ethanol overnight. Cells were centrifuged, washed with PBS, dissolved in $200 \mu \mathrm{L}$ of propidium iodide, and analyzed.

\section{Hoechst 33342 staining}

The Tca-8113 cells were washed in triplicate with PBS and fixed in $4 \%$ paraformaldehyde for 15 minutes at room temperature. The cells were washed with PBS for 5 minutes and incubated in Hoechst 33342 in the dark for 15 minutes at room temperature.

\section{Transwell migration and invasion assay}

Migration assays have been described previously in detail., ${ }^{6,23}$ Tca- 8113 cells $\left(1 \times 10^{5}\right.$ cells in $100 \mu \mathrm{L}$ DMEM supplemented with $1 \% \mathrm{FBS}$ ) were placed in the top chamber of transwell migration chambers ( $8 \mu \mathrm{M}$ BioCoat Control Inserts, BD). The lower chamber was filled with $600 \mu \mathrm{L}$ DMEM containing $10 \%$ FBS. Matrigel invasion assays were performed using modified Boyden chambers with polycarbonate Nuclepore membrane. Pre-coated filters $(6.5 \mathrm{~mm}$ in diameter, $8 \mu \mathrm{m}$ pore size, Matrigel $100 \mu \mathrm{g} / \mathrm{cm}^{2}$ ) were rehydrated with $100 \mu \mathrm{L}$ medium. Then, $1 \times 10^{5}$ cells in $100 \mu \mathrm{L}$ serum-free DMEM supplemented with $1 \%$ BSA were placed in the upper part of each chamber, whereas the lower compartments were filled with $600 \mu \mathrm{L}$ DMEM containing 10\% serum. After incubating for 18 hours at $37^{\circ} \mathrm{C}$, unmigrated cells or non-invaded cells were removed from the upper surface of the transwell membrane with a cotton swab, and migrated cells on the lower membrane surface were fixed, stained, photographed, and counted under high-power magnification.

\section{Statistical analysis}

All statistical analyses was performed using the SPSS 16.0 statistical software program (SPSS Inc., Chicago, IL, USA). Data were presented as the mean \pm standard deviation from at least three separate experiments. The statistical analysis correlation of data between groups was checked for significance by Student's $t$-test (two-tailed). Differences with $P<0.05$ were considered significant.

\section{Results}

\section{Carvacrol inhibits cell proliferation in human OSCC}

The chemical structure of carvacrol is a chemical compound 5-isopropyl-2-methylphenol with a molecular weight of 150
(Figure 1A). ${ }^{20,24} \mathrm{We}$ examined the effect of carvacrol on the proliferation of human Tca-8113 and SCC-25 cells using an MTT assay. Carvacrol treatment inhibited the proliferation of Tca-8113 and SCC-25 cells in a concentration-dependent manner (Figure 1B and C). Carvacrol had a significant impact on the cell cycle. A significant decrease in the S-phase (from $28.13 \%$ to $17.46 \%$ ) of Tca- 8113 cells treated with carvacrol $(40 \mu \mathrm{M})$ was observed when compared to control group cells (Figure 1D). These results indicate that carvacrol regulates the G1/S phases of the cell cycle in Tca- 8113 cancer cells and thus affects their proliferation pattern.

To investigate the mechanisms by which carvacrol inhibited the growth of human Tca-8113 cells, we next examined the expression profile of protein associated with cell proliferation by Western blotting assay. Strikingly, we found that exposure of Tca-8113 to carvacrol $(20,40$, and $80 \mu \mathrm{M})$ for 24 hours dramatically decreased levels of CCND1 and CDK4 protein expression compared to the DMSO-treated cells, which, in turn, increased the P21 expression in a concentration-dependent manner (Figure 1E). In contrast, expression of CDK2 and CKD6 was not affected under the same experimental conditions (Figure 1F). We further evaluated the effect of carvacrol on Tca-8113 cancer cells using colony formation assay. Colony formation assays showed much less colony formation in the carvacrol-treatment group (40 or $80 \mu \mathrm{M}$ ) compared with the control group (311 \pm 21 control group vs $175 \pm 1740 \mu \mathrm{M}$ group, $P<0.01 ; 311 \pm 21$ control group vs $142 \pm 27, P<0.01$ ) (Figure $1 \mathrm{G}$ ). These results indicated that carvacrol suppressed Tca-8113 cellular proliferation. Collectively, these findings indicate that carvacrol inhibits proliferation and may regulate Tca-8113 cancer cells through the reduction of cell cycle protein expression of CCND1 and CDK4 proteins and an increase in P21 levels.

\section{Carvacrol induces Tca-8 I I 3 cancer cells' apoptosis}

The following experiments demonstrated that carvacrol induced apoptosis, and we performed annexin V/propidium iodide staining on carvacrol-treated cells. The results showed that carvacrol could induce apoptosis of Tca-8113 cells in a dose-dependent manner. The cell proliferation inhibition effect was partly due to the promotion of apoptosis (Figure 2A). We therefore assessed the apoptosis-related protein expression of Bcl-2, Bax, and Cox2 in carvacroltreated Tca- 8113 cells. ${ }^{25}$ As shown in Figure 2B, carvacrol $(0,10,20,40,60$ or $80 \mu \mathrm{M})$ enhanced the levels of antiapoptotic proteins (Bcl-2) in Tca-8113 cells. In addition, in the Tca- 8113 cells that were exposed to carvacrol for 24 hours 
A<smiles>Cc1ccc(C(C)C)cc1O</smiles>

D

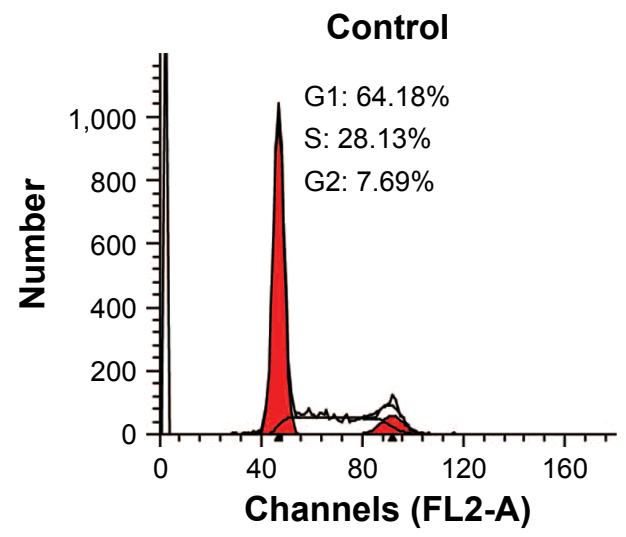

E

G

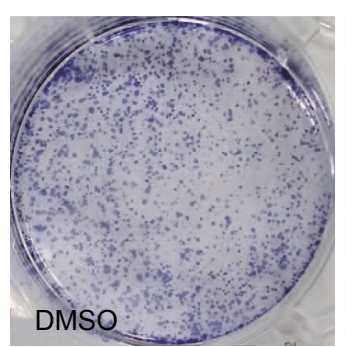

-actin
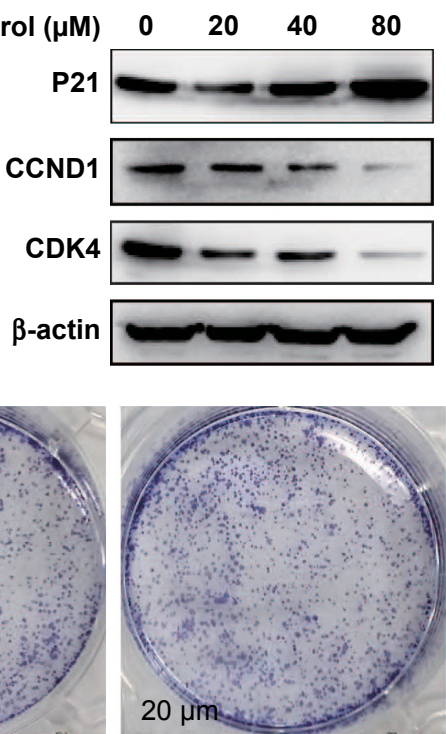

B

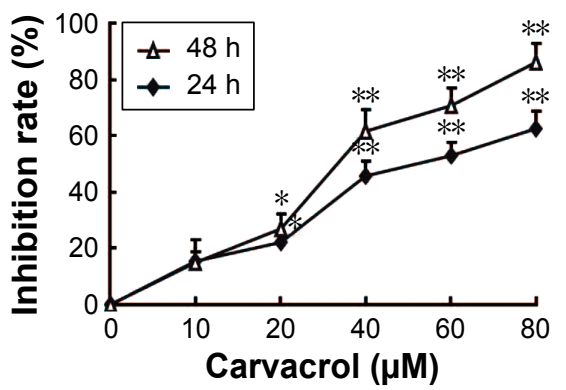

C

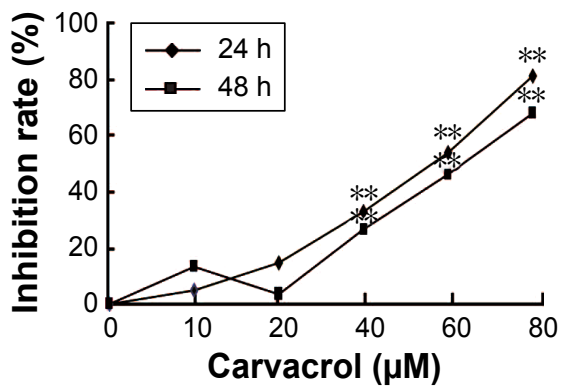

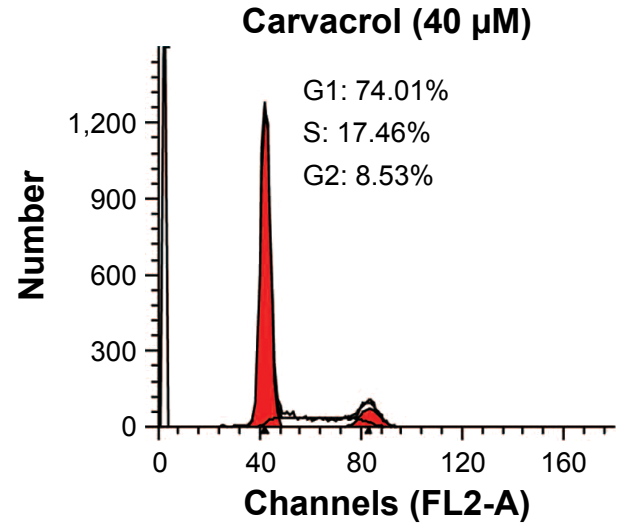

F

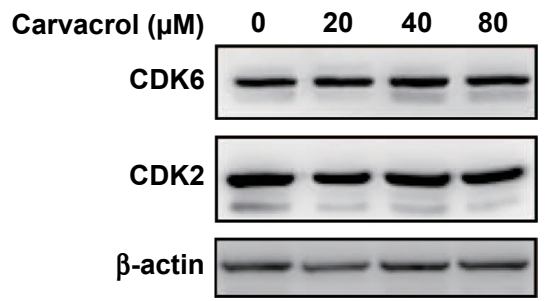

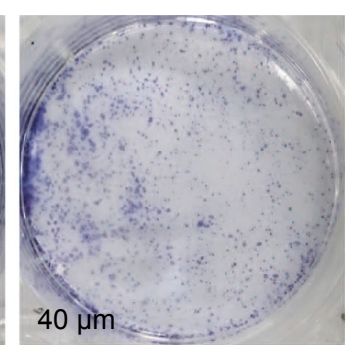

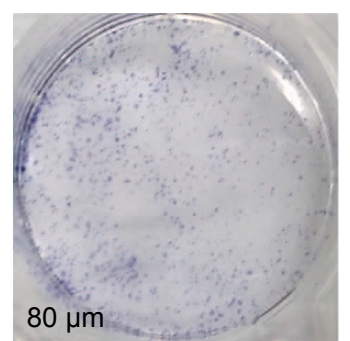

Figure I Carvacrol suppresses proliferation in human tongue cancer cells.

Notes: (A) Chemical structure of carvacrol (5-Isopropyl-2-methylphenol). Tca-8II3 cells (B) and SCC-25 cells (C) were cultured with the indicated concentrations of carvacrol in 96-well plates. After 24 hours (h), the cells were treated with MTT for 4 hours, and absorbance was measured. Results represent the mean \pm standard deviation of three experiments done in triplicate. ${ }^{*} P<0.05$, $* * P<0.01$ vs the Tca-8II3 control group. (D) Carvacrol reduces $\mathrm{S}$-phase of Tca-8II 3 cells compared to control cells. (E, F) Tca-8II 3 cells were treated with various concentrations of carvacrol (0 80 $\mu$ M) for 24 hours and then examined for expression of P2I, CCNDI, CDK4, and the unchanged expression of CDK2 and CDK6 by Western blot analysis. $\beta$-actin was used as an internal control for equal amount of total proteins. (G) Colony formation assay of Tca-8II 3 cells.

Abbreviation: DMSO, dimethyl sulfoxide.

$(0,10,20,40,60$ or $80 \mu \mathrm{M})$, the level of proapoptotic proteins Bax and Cox 2 decreased. The morphologic changes were examined by Hoechst 33258 staining (Figure 2C). After Tca-8113 cells were treated with $20 \mu \mathrm{M}$ carvacrol for 24 hours, the apoptotic morphologic changes were observed as compared with the control. In the control group, the nuclei of Tca-8113 cells were round and homogeneously stained while carvacrol-treated cells exhibited evident characteristics of apoptosis. Together, these findings indicate that carvacrol inhibits growth of Tca-8113 cells by inducing apoptosis. 
A
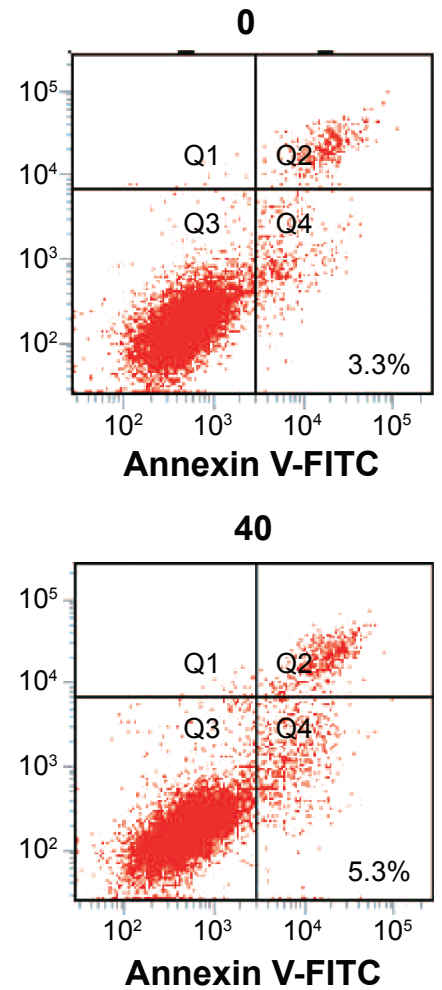

B

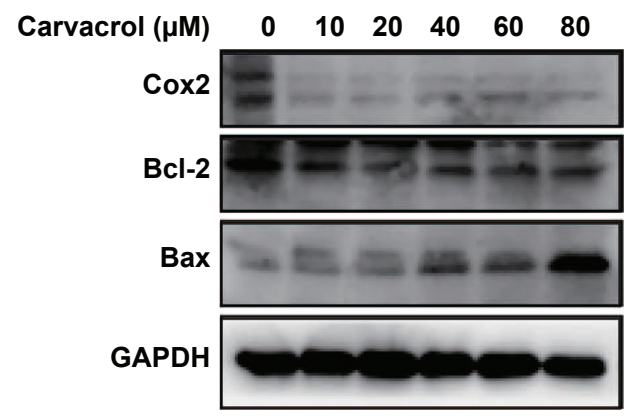

Carvacrol ( $\mu \mathrm{M})$

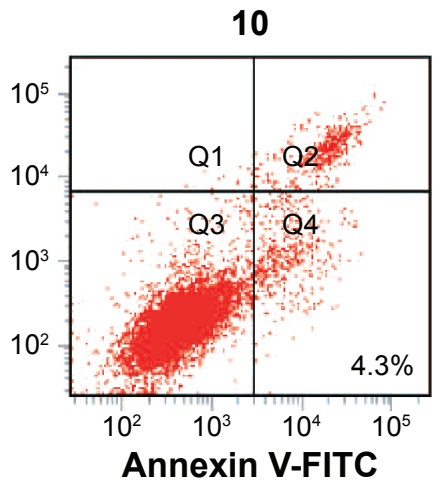

60

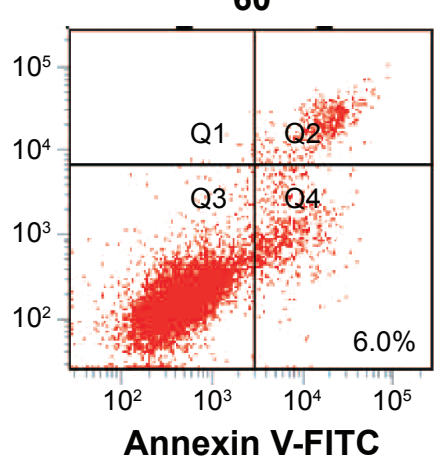

C Hoechst 33258
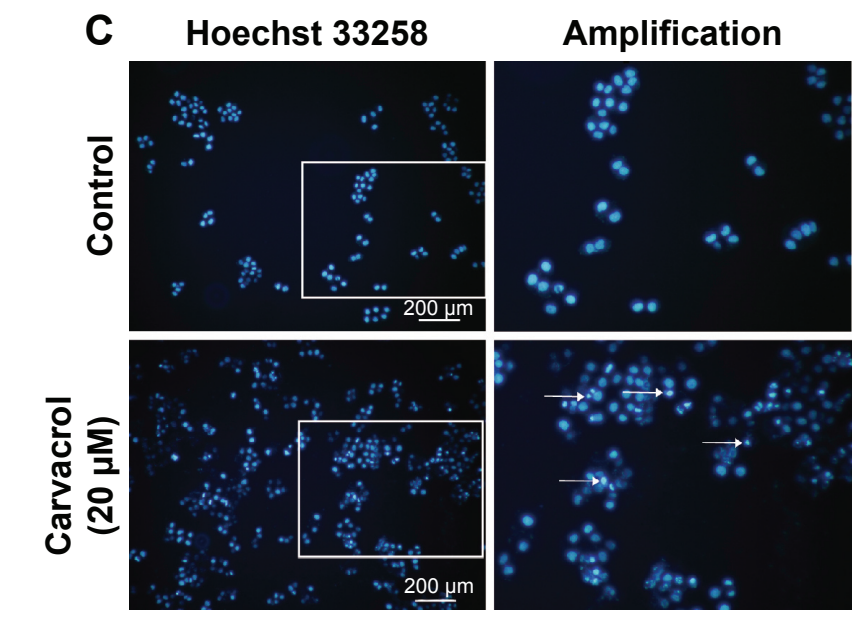

20

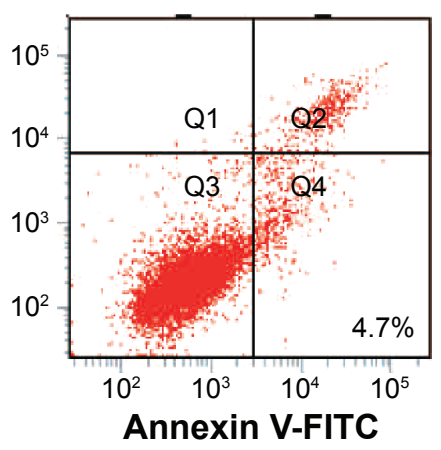

80

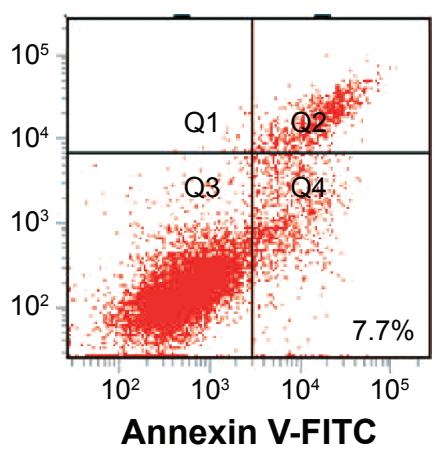

Figure 2 Carvacrol promoted cell apoptosis in Tca-8 I 3 cells.

Notes: (A) The percentage of apoptotic cells was quantitated by flow cytometry. (B) The expression of Cox2, Bcl-2, and Bax proteins was analyzed by Western blotting. (C) Tca-8II 3 cells treated with carvacrol were subjected to Hoechst 33258 staining and viewed under a microscope. Arrows show apoptotic morphologic changes (chromatin condensed). (Original magnification: $\times 100)$.

\section{Carvacrol inhibits Tca-8I I3 cancer cell adhesion ability}

To investigate whether carvacrol can influence the ability of Tca-8113 cancer cell invasion, we treated the Tca-8113 cancer cell lines with different concentrations of carvacrol. Carvacrol negatively regulates Tca- 8113 cancer cell adhesion to fibronectin compared to control group cells. After 60 minutes' or 100 minutes' incubation, when comparing carvacrol-treated Tca-8113 cells with control group cells, carvacrol-treated $(80 \mu \mathrm{M})$ Tca-8113 cells resulted in a significant decrease in adhesion of approximately $50 \%$ or $60 \%$ to fibronectin, respectively (Figure 3A, B).

\section{Carvacrol inhibits Tca-8 I I 3 cell migration and invasion}

Thus, the above results suggested that carvacrol could repress Tca-8113 cancer cell migration and invasion. Moreover, to explore the invasion-related downstream molecules regulated by carvacrol, we checked the expression levels of FAK and p-FAK in carvacrol-treated Tca-8113 cancer 
A

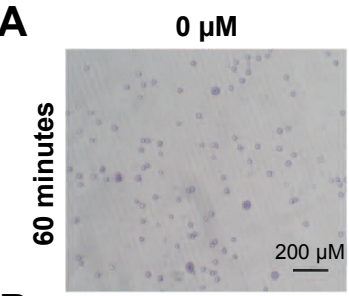

B

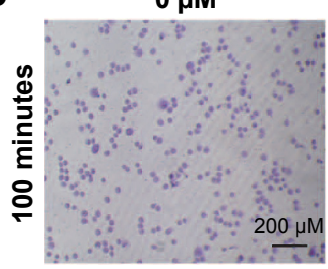

$40 \mu \mathrm{M}$

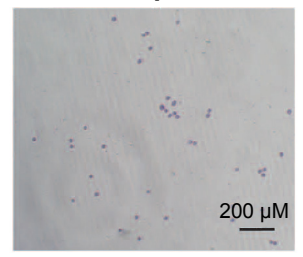

$40 \mu \mathrm{M}$

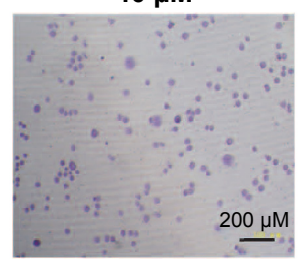

$80 \mu \mathrm{M}$

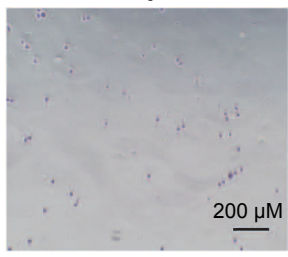

$80 \mu \mathrm{M}$

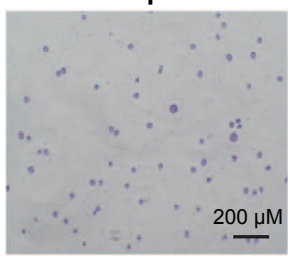

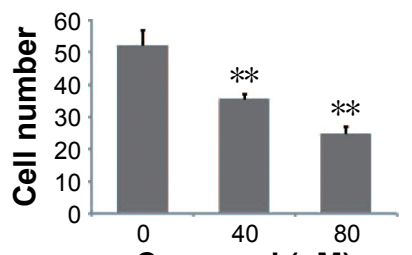

Carvacrol ( $\mu \mathrm{M})$

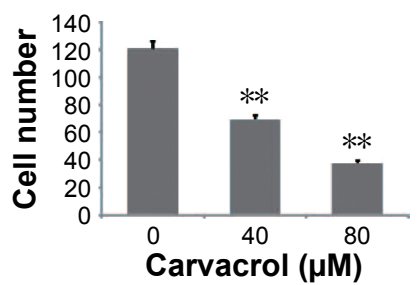

Figure 3 Carvacrol inhibited the adherence of Tca-8 I 3 cancer cells.

Notes: Cells' adherence force was evaluated by adherence assay in 60 minutes (A) or 100 minutes (B). The attached cells were fixed and stained, and ten random fields were counted. Magnification $\times 200$. Scale bars: $200 \mu$ M. Also shown is the number of adherent cells from three independent experiments. $* * P<0.01$ using Student's $t$-test.

cells by Western blotting. The results showed that the phosphorylation level of FAK was significantly decreased (Figure 4A). Furthermore, carvacrol treatment decreased the expression of epithelial-mesenchymal transition-related transcription factors $\beta$-catenin and $\mathrm{ZEB}-1^{26}$ in a dose-dependent

\section{A}

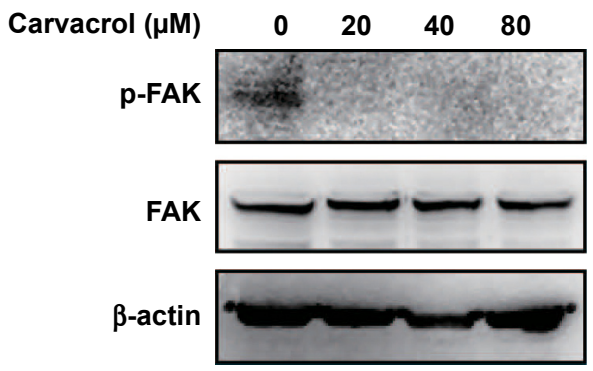

D

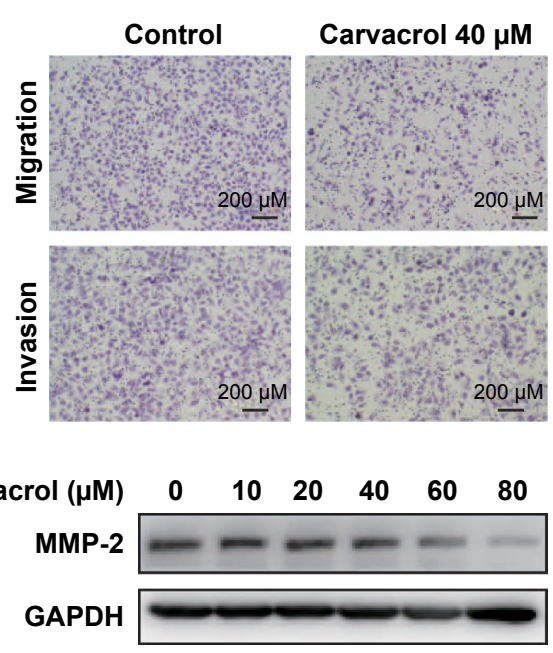

manner (Figure 4B, C). Transwell assay was used to determine whether carvacrol affects the invasiveness of Tca-8113 cells. As shown in Figure 4D and E, carvacrol treatment resulted in reduced cell migration and invasion from the top to the bottom chamber compared with the control cells,

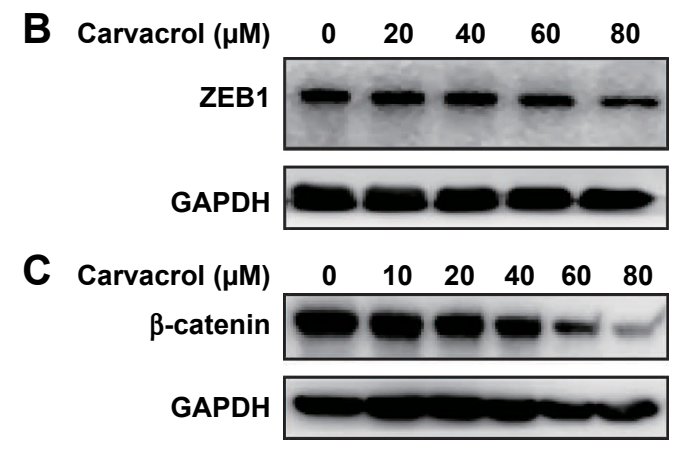

E
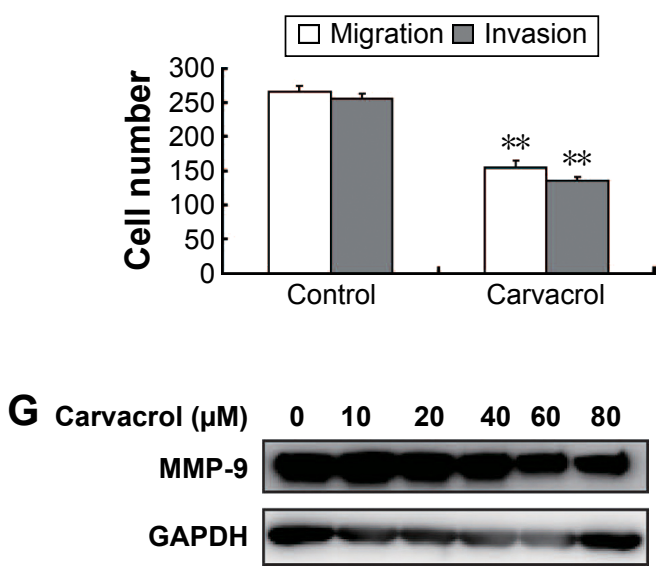

Figure 4 Carvacrol inhibits Tca-8I I3 cell migration and invasion.

Notes: (A) The expression of p-FAK and FAK proteins was analyzed by Western blotting in carvacrol-treated Tca-8II3 cells. (B, C) Expression of $\beta$-catenin and ZEBI in carvacrol-treated Tca-8II 3 cells. Then, Tca-8II 3 cells were treated by control or $40 \mu$ of carvacrol for 24 hours, respectively. (D) Transwell assay analyses of the migration or invasion potential of Tca-8II3 cells. Magnification $\times 200$. (E) Numbers of migratory or invasive cells (mean \pm standard deviation, $n=5$, " $n$ " means five randomly chosen fields). $* * P<0.01$. (F, G) Tca-8I I 3 cells were treated with 0 to $80 \mu \mathrm{M}$ of carvacrol for 24 hours. MMP-2 and MMP-9 levels were determined by Western blotting. 
suggesting that carvacrol suppresses the migration and invasion capability. Furthermore, MMP-2 and MMP-9 protein expression was dramatically suppressed in Tca-8113 cells treated with carvacrol (Figure 4F, G). We conclude that carvacrol is essential in Tca-8113 cell migration and invasion. Taken together, these results indicated that carvacrol inhibited Tca-8113 cell migration and invasion properties by inhibiting P-FAK and the reduction of $\beta$-catenin, ZEB1, and MMP-2/9 expression.

\section{Discussion}

Patients with OSCC now have an overall 5-year survival rate of approximately $25 \% .{ }^{27}$ Natural products have been an advancing development of new anticancer drugs after the advent of molecular biology and chemical compounds to target specific molecules. Carvacrol was the first identified application in cancer therapy, which inhibits growth of myoblast cells even after activation of mutated N-ras oncogene. ${ }^{28}$ Our results suggested that carvacrol is a novel, potent, natural anticancer drug for human OSCC. It could suppress human OSCC cancer cells' proliferation via a series of biological pathways including cell cycle regulation, apoptosis, tumorigenesis, adhesion, and invasion. ${ }^{29,30}$ Accumulating evidence suggests that carvacrol may have therapeutic potential for the prevention and treatment of cancer, including colon cancer, ${ }^{20}$ hepatoma, ${ }^{31}$ and breast cancer. ${ }^{19}$

Recently, Arunasree reported that carvacrol has an antiproliferative effect in human metastatic breast cancer cells. ${ }^{19}$ Fan et al suggested that carvacrol inhibited the proliferation and migration in human colon cancer cell lines in a dosedependent manner. ${ }^{20}$ Subramaniyan et al indicated that carvacrol exhibited the potential anticancer activity by inhibiting cell proliferation and preventing metastasis in diethylnitrosamine-induced hepatocellular carcinogenesis. ${ }^{32}$ In subsequent exploration and analysis, we found that carvacrol effectively inhibits the proliferation of Tca-8113 cells through downregulating the expression of CCND1 and CDK4 and upregulating the expression of P21. Additionally, the MTT assay and colony formation assays illustrated the function of carvacrol in cell growth and proliferation. Generally, apoptosis is closely associated with tumorigenesis. We then evaluated the cell apoptosis of carvacrol-treated Tca- 8113 cells by flow cytometry and Western blotting assay. We observed accelerated apoptosis when Tca- 8113 cells were treated with carvacrol and an increased ratio of Bax/Bcl-2 was detected in carvacrol-treated Tca- 8113 cells, suggesting that carvacrol promotes apoptosis in Tca-8113 cells.

In addition to the effect on cell proliferation and cell apoptosis, we also demonstrated the inhibitory effect on cell migration and invasion of carvacrol on OSCC cells. OSCC is an aggressive disease and a large majority of cancer deaths result from local metastases and distant sites beyond the primary tumor, which are poorly controlled by surgery. FAK is an important protein tyrosine kinase involved in cancer cell invasion and metastasis. ${ }^{33}$ In this study, we found that carvacrol could inhibit activation of FAK activity, suggesting that carvacrol inhibits FAK signaling pathways. Our results showed that carvacrol significantly suppressed the migratory and invasive ability of Tca-8113 cancer cells parallel with downregulation of ZEB1 and $\beta$-catenin proteins. Then, we found that carvacrol treatment dose-dependently downregulated MMP-2/9 proteins' expression.

In summary, carvacrol, a natural anticancer agent, was identified to be capable of inhibiting OSCC cell behaviors including proliferation, migration, and invasion. However, these results warrant further testing in experimental models in vivo, and the present findings do support the conception that carvacrol may be a novel approach for the treatment of OSCC patients.

\section{Acknowledgments}

This work has been supported by grants from the National Natural Science Foundation of China (numbers 81301835, 81372337,31201053 ) and the National Natural Science Foundation of Liaoning Province (number 2015020528). The funders had no role in study design, data collection and analysis, decision to publish, or preparation of the manuscript.

\section{Disclosure}

The authors have no conflicts of interest to disclose.

\section{References}

1. Maji S, Samal SK, Pattanaik L, et al. Mcl-1 is an important therapeutic target for oral squamous cell carcinomas. Oncotarget. 2015;6(18): 16623-16637.

2. He Q, Liu Z, Zhao T, Zhao L, Zhou X, Wang A. Bmil drives stem-like properties and is associated with migration, invasion, and poor prognosis in tongue squamous cell carcinoma. Int J Biol Sci. 2015;11(1):1-10.

3. LiZ, Wang Y, Qiu J, et al. The polycomb group protein EZH2 is a novel therapeutic target in tongue cancer. Oncotarget. 2013;4(12):2532-2549.

4. Li H, Zhang Y, Cao L, et al. Curcumin could reduce the monomer of TTR with Tyr114Cys mutation via autophagy in cell model of familial amyloid polyneuropathy. Drug Des Devel Ther. 2014;8:2121-2128.

5. Metelmann HR, Hyckel P, Podmelle F. Oral cancer treatment and immune targets - a role for dendritic cells? J Craniomaxillofac Surg. 2012; 40(2):103-104.

6. Dai W, Li Y, Zhou Q, et al. Cetuximab inhibits oral squamous cell carcinoma invasion and metastasis via degradation of epidermal growth factor receptor. J Oral Pathol Med. 2014;43(4):250-257.

7. Ultee A, Slump RA, Steging G, Smid EJ. Antimicrobial activity of carvacrol toward Bacillus cereus on rice. J Food Prot. 2000;63(5):620-624

8. Baser KH. Biological and pharmacological activities of carvacrol and carvacrol bearing essential oils. Curr Pharm Des. 2008;14(29): 3106-3119. 
9. Guimaraes AG, Oliveira MA, Alves Rdos S, et al. Encapsulation of carvacrol, a monoterpene present in the essential oil of oregano, with beta-cyclodextrin, improves the pharmacological response on cancer pain experimental protocols. Chem Biol Interact. 2015;227:69-76.

10. Guimaraes AG, Scotti L, Scotti MT, et al. Evidence for the involvement of descending pain-inhibitory mechanisms in the attenuation of cancer pain by carvacrol aided through a docking study. Life Sci. 2014; 116(1):8-15.

11. Guimaraes AG, Xavier MA, de Santana MT, et al. Carvacrol attenuates mechanical hypernociception and inflammatory response. Naunyn Schmiedebergs Arch Pharmacol. 2012;385(3):253-263.

12. Boskabady MH, Tabanfar H, Gholamnezhad Z, Sadeghnia HR. Inhibitory effect of Zataria multiflora Boiss and carvacrol on histamine (H(1)) receptors of guinea-pig tracheal chains. Fundam Clin Pharmacol. 2012;26(5):609-620.

13. Gholami Mahtaj L, Boskabady MH, Mohamadian Roshan N. The Effect of Zataria multiflora and its Constituent, Carvacrol, on Tracheal Responsiveness and Lung Pathology in Guinea Pig Model of COPD. Phytother Res. 2015;29(5):730-736.

14. Boskabady MH, Gholami Mahtaj L. Lung inflammation changes and oxidative stress induced by cigarette smoke exposure in guinea pigs affected by Zataria multiflora and its constituent, carvacrol. BMC Complement Altern Med. 2015;15:39.

15. Boskabady MH, Jalali S. Effect of carvacrol on tracheal responsiveness, inflammatory mediators, total and differential WBC count in blood of sensitized guinea pigs. Exp Biol Med (Maywood). 2013;238(2): 200-208.

16. Jalali S, Boskabady MH, Haeri Rohani A, Eidi A. The effect of carvacrol on serum cytokines and endothelin levels of ovalbumin sensitized Guinea-pigs. Iran J Basic Med Sci. 2013;16(4):615-619.

17. Mahtaj LG, Feizpour A, Kianmehr M, Soukhtanloo M, Boskabady MH. The effect of carvacrol on systemic inflammation in guinea pigs model of COPD induced by cigarette smoke exposure. Pharmacol Rep. 2015;67(1):140-145.

18. Koparal AT, Zeytinoglu M. Effects of Carvacrol on a Human NonSmall Cell Lung Cancer (NSCLC) Cell Line, A549. Cytotechnology. 2003;43(1-3):149-154.

19. Arunasree KM. Anti-proliferative effects of carvacrol on a human metastatic breast cancer cell line, MDA-MB 231. Phytomedicine. 2010; 17(8-9):581-588.

20. Fan K, Li X, Cao Y, et al. Carvacrol inhibits proliferation and induces apoptosis in human colon cancer cells. Anticancer Drugs. 2015;26(8): 813-823.

21. Tokyol C, Aktepe F, Dilek FH, Sahin O, Arioz DT. Expression of cyclooxygenase-2 and matrix metalloproteinase-2 in adenomyosis and endometrial polyps and its correlation with angiogenesis. Int J Gynecol Pathol. 2009;28(2):148-156.
22. Yang J, Weinberg RA. Epithelial-mesenchymal transition: at the crossroads of development and tumor metastasis. Dev Cell. 2008;14(6): 818-829.

23. Yao Y, Feng S, Xiao M, Li Y, Yang L, Gong J. MTA1 promotes proliferation and invasion in human gastric cancer cells. OncoTargets Ther. 2015;8:1785-1794.

24. Arigesavan K, Sudhandiran G. Carvacrol exhibits anti-oxidant and anti-inflammatory effects against 1,2-dimethyl hydrazine plus dextran sodium sulfate induced inflammation associated carcinogenicity in the colon of Fischer 344 rats. Biochem Biophys Res Commun. 2015; 461(2):314-320.

25. Seyedmajidi M, Shafaee S, Siadati S, Khorasani M, Bijani A, Ghasemi N. Cyclo-oxygenase-2 expression in oral squamous cell carcinoma. J Cancer Res Ther. 2014;10(4):1024-1029.

26. Agajanian M, Runa F, Kelber JA. Identification of a PEAK1/ZEB1 signaling axis during TGFbeta/fibronectin-induced EMT in breast cancer. Biochem Biophys Res Commun. 2015;465(3):606-612.

27. Ramqvist T, Dalianis T. Oropharyngeal cancer epidemic and human papillomavirus. Emerg Infect Dis. 2010;16(11):1671-1677.

28. Zeytinoglu H, Incesu Z, Baser KH. Inhibition of DNA synthesis by carvacrol in mouse myoblast cells bearing a human N-RAS oncogene. Phytomedicine. 2003;10(4):292-299.

29. Saito T, Kasamatsu A, Ogawara K, et al. Semaphorin7A Promotion of Tumoral Growth and Metastasis in Human Oral Cancer by Regulation of G1 Cell Cycle and Matrix Metalloproteases: Possible Contribution to Tumoral Angiogenesis. PloS One. 2015;10(9):e0137923.

30. Jeon YJ, Ko SM, Cho JH, Chae JI, Shim JH. The HDAC inhibitor, panobinostat, induces apoptosis by suppressing the expression of specificity protein 1 in oral squamous cell carcinoma. Int J Mol Med. 2013; 32(4):860-866.

31. Melusova M, Jantova S, Horvathova E. Carvacrol and rosemary oil at higher concentrations induce apoptosis in human hepatoma HepG2 cells. Interdiscip Toxicol. 2014;7(4):189-194.

32. Subramaniyan J, Krishnan G, Balan R, et al. Carvacrol modulates instability of xenobiotic metabolizing enzymes and downregulates the expressions of PCNA, MMP-2, and MMP-9 during diethylnitrosamineinduced hepatocarcinogenesis in rats. Mol Cell Biochem. 2014; 395(1-2):65-76.

33. Kornberg LJ. Focal adhesion kinase and its potential involvement in tumor invasion and metastasis. Head Neck. 1998;20(8):745-752.
OncoTargets and Therapy

\section{Publish your work in this journal}

OncoTargets and Therapy is an international, peer-reviewed, open access journal focusing on the pathological basis of all cancers, potential targets for therapy and treatment protocols employed to improve the management of cancer patients. The journal also focuses on the impact of management programs and new therapeutic agents and protocols on

\section{Dovepress}

patient perspectives such as quality of life, adherence and satisfaction The manuscript management system is completely online and includes a very quick and fair peer-review system, which is all easy to use. Visit http://www.dovepress.com/testimonials.php to read real quotes from published authors. 